\title{
A Dynamic Model for Direct and Indirect Matrix Converters
}

\author{
Mohamad Hosseini Abardeh and Reza Ghazi \\ Electrical Engineering Department, Faculty of Engineering, Ferdowsi University of Mashhad, P.O. Box 9177948974, Mashhad, Iran
}

Correspondence should be addressed to Mohamad Hosseini Abardeh; mohamad.hosseinil@gmail.com

Received 29 September 2013; Revised 1 March 2014; Accepted 20 March 2014; Published 8 April 2014

Academic Editor: Don Mahinda Vilathgamuwa

Copyright (C) 2014 M. Hosseini Abardeh and R. Ghazi. This is an open access article distributed under the Creative Commons Attribution License, which permits unrestricted use, distribution, and reproduction in any medium, provided the original work is properly cited.

\begin{abstract}
The complicated modulation algorithm and the high switching frequency are two main hindrances in the analysis and simulation of matrix converters (MCs) based systems. To simplify the analysis and accelerate the simulation of MCs, a unique dynamic model is presented for the MC, which is independent of MC type (direct or indirect) and the modulation algorithm. All the input and output variables are transferred to the respective reference frames and their relations and limits are calculated. Based on the proposed equations, an equivalent circuit model is presented which can predict all the direct and indirect matrix converters dynamic and steady state behaviors without the need for small simulation time steps. Validity of the proposed model is evaluated using simulation of the precise model. Moreover, experimental results from a laboratory matrix converter setup are provided to verify the accuracy of the simulation results.
\end{abstract}

\section{Introduction}

The need for AC-AC power conversion is, rapidly, increasing. The power electronics converters are used for generating variable amplitude, frequency, and phase voltages and currents [1].

Matrix converter (MC) is an all-switch power converter with interesting properties such as controllable input power factor, bidirectional power flow, and high quality input and output currents. Moreover, because of the absence of the bulky DC link energy storage component, it benefits from the possibility of a compact design $[2,3]$. As shown in Figure 1, there are two main types for the MC, namely, direct matrix converter (DMC) and indirect matrix converter (IMC). The application of these converters are extensive: motor drive $[4,5]$, FACTS devices [6-8], distributed generation systems $[9,10]$, and wind energy conversion systems $[11,12]$.

The MC switching states are determined by modulation algorithms. Different modulation algorithms such as AlesinaVenturini (AV) method, optimum AV method, space vector modulation (SVM) [13], and duty cycle space vector (DCSV) $[14,15]$ have been proposed. In all cases, the modulation of the matrix converter is a complicated task and the switching frequency is usually in order of $\mathrm{kHz}$ (up to $45 \mathrm{kHz}$ ) [16].
Therefore, simulation of any MC based system is a timeconsuming process, specially when the switching frequency is high. However, in dynamic and steady state studies, there is no need to consider the switching behavior of the converter regarding the study timescale. Moreover, in analytical methods for dynamic and steady state evaluation of the MC, only the knowledge of input-output relationship between voltages and currents is adequate. In these cases, by replacing the MC precise model with a dynamic model, the need for simulation and calculation of the converter switches operation is canceled out. As a consequence, the whole processes of evaluation and simulation of MC based systems become easier and much faster.

The dynamic model of power electronics converters based on methods such as averaging and principle of energy conservation is a well-known issue [17, 18]. Using these methods, different models have been presented for the matrix converters [19-23]. A dynamic model in a rotating $d q 0$ frame is presented in [19]. This model is then linearized and a controller is designed on this basis. However, this model needs the knowledge of input network and the load parameters to work precisely. A dynamic model for space vector modulated MC in two independent input and output sides direct- and quadrature-axis reference frames has been developed in [20]. 
Although the model is independent of the source and load parameters, but its application is limited to the MCs using SVM algorithm. An equivalent circuit and a state space dynamic models for a direct matrix converter (DMC) based on the modulation matrix are proposed [21] where the input and output sides are modeled by three dependent current and voltage sources. A modeling algorithm based on the singular value decomposition (SVD) of the averaged switching matrix is presented in [22]. This method is independent of the modulation algorithm. A model based on switching state matrix averaging is presented for DMC in [23] to accelerate the fixed step simulation. It is shown that using this method the interval between simulation iterations increases from less than 250 ns up to $10 \mu \mathrm{s}$.

So far, the all proposed dynamic models are dependent on the converter structure (MC and IMC) and the modulation algorithm. To solve these difficulties, in this paper, a unique dynamic model for both structures of matrix converters (direct and indirect) is developed. In this model, the MC output to input voltage ratio which is independent of the modulation algorithm is used to relate the system variables. Therefore, the model besides being unique is independent of the modulation algorithm and it can be applied in various applications. In addition to the above benefits, the difficulties arising from the high frequency switches and complicated modulation algorithm are solved and the process of dynamic evaluation and simulation is greatly accelerated. The main differences between proposed model and space vector models of $\mathrm{MC}$ (such as the model presented in $[14,15]$ ) are the following: (1) in proposed model, the switching of converter is ignored since the steady state and dynamic performances are intended, and (2) to enable control of input currents and output voltages, space vector models of the switching states are calculated by SVM; but the proposed model supposes that the modulation algorithm is working properly, and to assess the dynamic performance of the MC based systems only the input and output voltages and currents need to be calculated.

This paper begins with presentation of the matrix converter model and the equivalent circuit in Section 2. The simulation results based on the proposed model for the MC and the IMC are discussed in Section 3. In Section 4, the laboratory setup details and results are presented. Section 5 concludes the paper.

\section{Matrix Converter Model}

The direct and indirect matrix converter schemes are shown in Figure $1[3,24]$. The direct matrix converters perform $\mathrm{AC} / \mathrm{AC}$ power conversion in a single stage, while the indirect matrix converters do it in two stages, namely, rectification and inversion stages. The rectifier stage provides a fictitious DC link voltage with a variable average. The inverter stage synthesizes three-phase output voltages. The switching pattern can be constructed using different methods such as Venturini, space vector, and sawtooth wave modulations.

The concern of this paper is the fundamental frequency component of the MC input and output voltages and currents. Therefore, the switching effects are neglected. Based on the

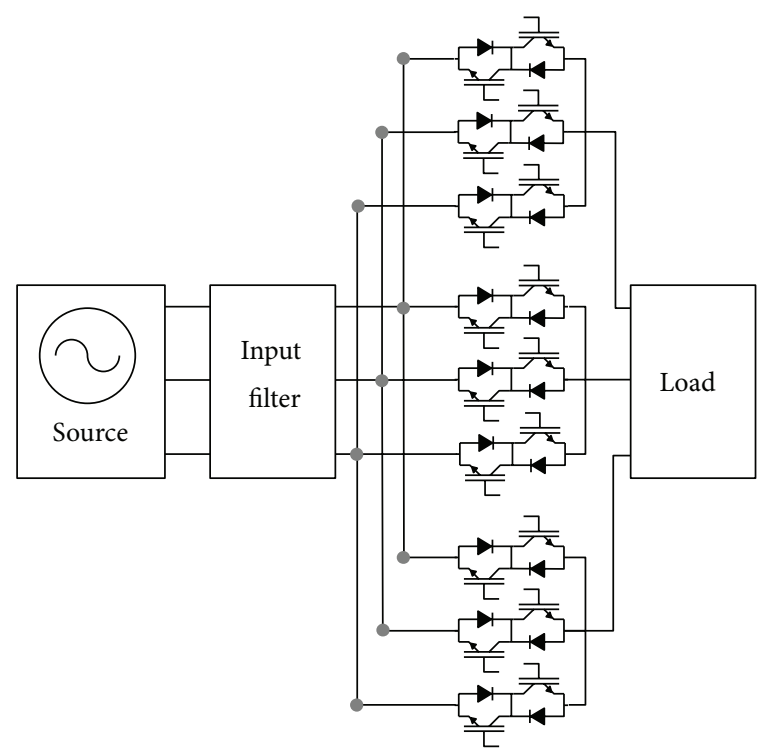

(a)

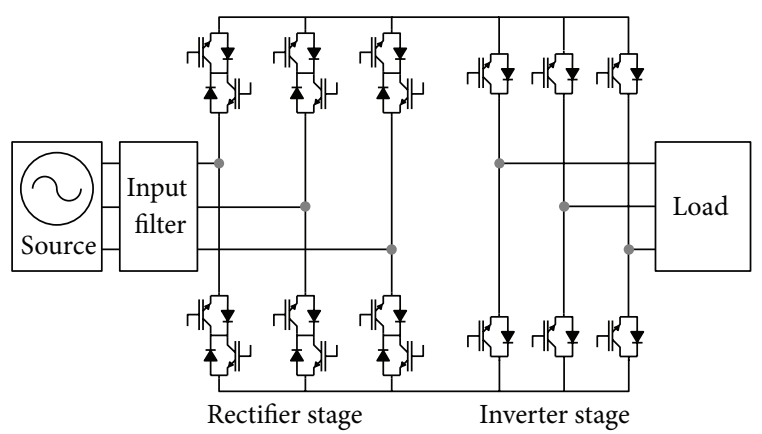

(b)

FIGURE 1: Schematic circuit of (a) direct matrix converter, and (b) indirect matrix converter.

energy conservation rule, we have the following equation; wherein $P_{\text {in }}$ and $P_{\text {out }}$ are the input and the output active power of the MC,

$$
P_{\text {in }}=P_{\text {out }} \text {. }
$$

Transferring all the input and output voltages and currents into the respective $d q$ rotating reference frames having the input and output sides angular speed, (1) leads to

$$
v_{i d} i_{i d}+v_{i q} i_{i q}=v_{o d} i_{o d}+v_{o q} i_{o q}
$$

where subscripts " $i$ " and " $o$ " refer to the input and output quantities and subscripts " $d$ " and " $q$ " refer to direct and quadrature axis of the rotating reference frame. The input side $d q$ frame is coincident with the input voltage; that is, $v_{i q}=0$. Equation (2) can be rewritten as follows:

$$
i_{i d}=\frac{v_{o d}}{v_{i d}} i_{o d}+\frac{v_{o q}}{v_{i d}} i_{o q} .
$$

The MC input to output voltage ratio is

$$
q=\frac{V_{o m}}{V_{i m}}
$$


where $V_{\text {om }}$ and $V_{\text {im }}$ are the output and input voltages amplitudes defined by

$$
\begin{aligned}
& V_{i m}=\sqrt{v_{i d}^{2}+v_{i q}^{2}}, \\
& V_{o m}=\sqrt{v_{o d}^{2}+v_{o q}^{2}} .
\end{aligned}
$$

By defining the output voltage space vector as

$$
\vec{v}_{o}=v_{o d}+j v_{o q}
$$

substituting (6) in (4) yields

$$
q=\frac{\sqrt{v_{o d}^{2}+v_{o q}^{2}}}{v_{i d}}
$$

The direct and quadrature components of $q$ can be defined as

$$
\begin{gathered}
q_{d}=\frac{v_{o d}}{v_{i d}}, \\
q_{q}=\frac{v_{o q}}{v_{i d}}, \\
q=\sqrt{q_{d}^{2}+q_{q}^{2}} .
\end{gathered}
$$

Substituting (8) in (3), we have

$$
i_{i d}=q_{d} i_{o d}+q_{q} i_{o q}
$$

For unity power factor at the input side, we have

$$
i_{i q}=0 \text {. }
$$

As the matrix converter does not always operate at unity input power factor, to have a general dynamic model, the nonzero value $i_{i q}$ must be calculated. Equation (1) can be represented by the following form:

$$
V_{i m} I_{i m} \cos \left(\phi_{i}\right)=V_{o m} I_{o m} \cos \left(\phi_{o}\right),
$$

where $\cos \left(\phi_{i}\right)$ and $\cos \left(\phi_{o}\right)$ are the input and output sides power factors and

$$
\begin{aligned}
& I_{i m}=\sqrt{i_{i d}^{2}+i_{i q}^{2}}, \\
& I_{o m}=\sqrt{i_{o d}^{2}+i_{o q}^{2}} .
\end{aligned}
$$

Substituting (5), (13), and (8) into (12) and after some manipulations, we obtain

$$
i_{i q}=\left(\left(q_{d}^{2}+q_{q}^{2}\right) \frac{\cos \left(\phi_{o}\right)}{\cos \left(\phi_{i}\right)}-\left(q_{d} i_{o d}+q_{q} i_{o q}\right)^{2}\right)^{1 / 2} .
$$

The input power factor is known in the modulation algorithm, but the output power factor is unknown. Substituting (2) into (12) and after some manipulations, we have

$$
\cos \left(\phi_{o}\right)=\frac{v_{o d} i_{o d}+v_{o q} i_{o q}}{\left(v_{o d}^{2}+v_{o q}^{2}\right)^{1 / 2}\left(i_{o d}^{2}+i_{o q}^{2}\right)^{1 / 2}} .
$$

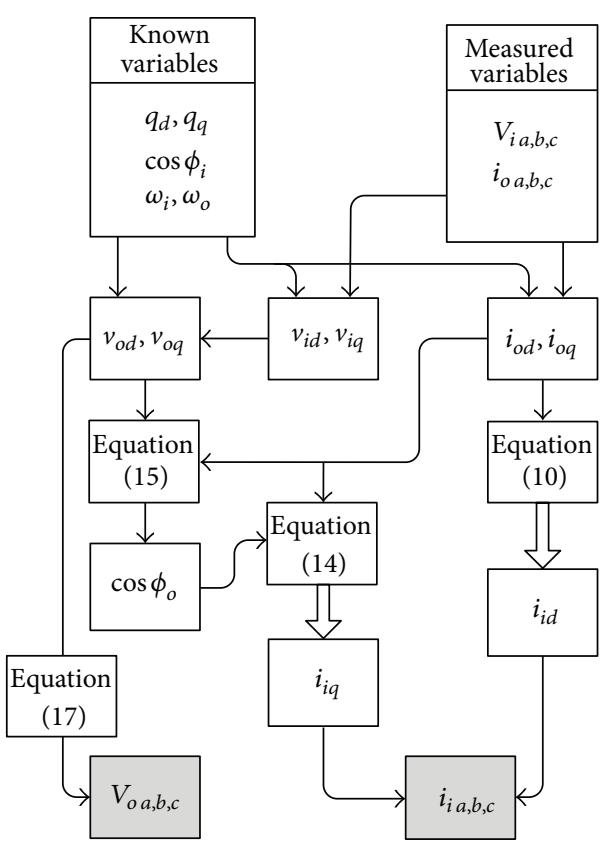

FIGURE 2: Proposed algorithm for calculation of the dynamic model variables.

Two constraints will limit the MC operation. The first one is the maximum voltage ratio 0.87 at unity power factor. The second constraint is the reduction of the maximum voltage ratio with input power factor variation according to

$$
q_{\max }=0.87 \cos \left(\phi_{i}\right),
$$

where $q_{\max }$ is the maximum voltage ratio when the input power factor is equal to $\cos \left(\phi_{i}\right)$. Substituting (16) into (8) and after some manipulations, we have

$$
\begin{gathered}
v_{o d-\max } \leq q_{d-\max } \times v_{i d}, \\
v_{o q-\max } \leq \sqrt{q_{d-\max }^{2}-\left(0.87 \cos \left(\phi_{i}\right)\right)^{2}} \times v_{i d},
\end{gathered}
$$

where subscript "max" denotes the maximum value of the variable.

Figure 2 shows how measured quantities (three-phase input voltages, $v_{i a, b, c}$, and three-phase output currents, $i_{o a, b, c}$ ) are used to calculate the intermediate and output variables of the model.

\section{Simulation Results}

To evaluate the proposed model, direct and indirect matrix converters have been simulated using PSCAD/EMTDC software. All results are produced by setting $2 \mu \mathrm{s}$ as the simulation time step. Figure 1 shows the benchmark system and the parameters are presented in Table 1. The input filter is RLC type and the MC switching frequency is $2.0 \mathrm{kHz}$. Space vector modulation (SVM) is used as it is compatible with digital microcontroller implementation. Inductance and capacitance of the input filter are $1 \mathrm{mH}$ and $40 \mu \mathrm{F}$; therefore, the filter cut-off frequency is $795 \mathrm{~Hz}$ which is well below 


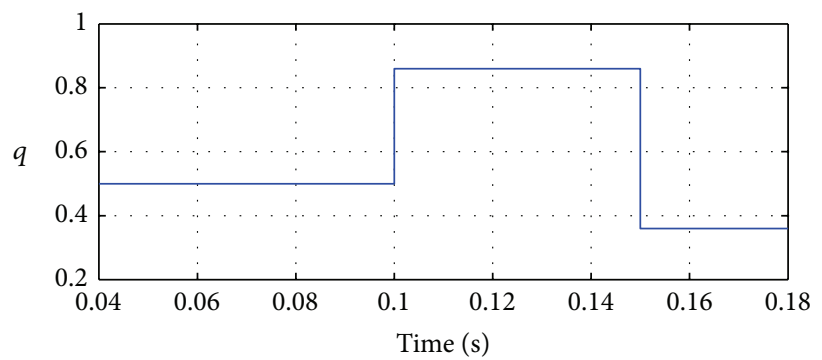

(a)
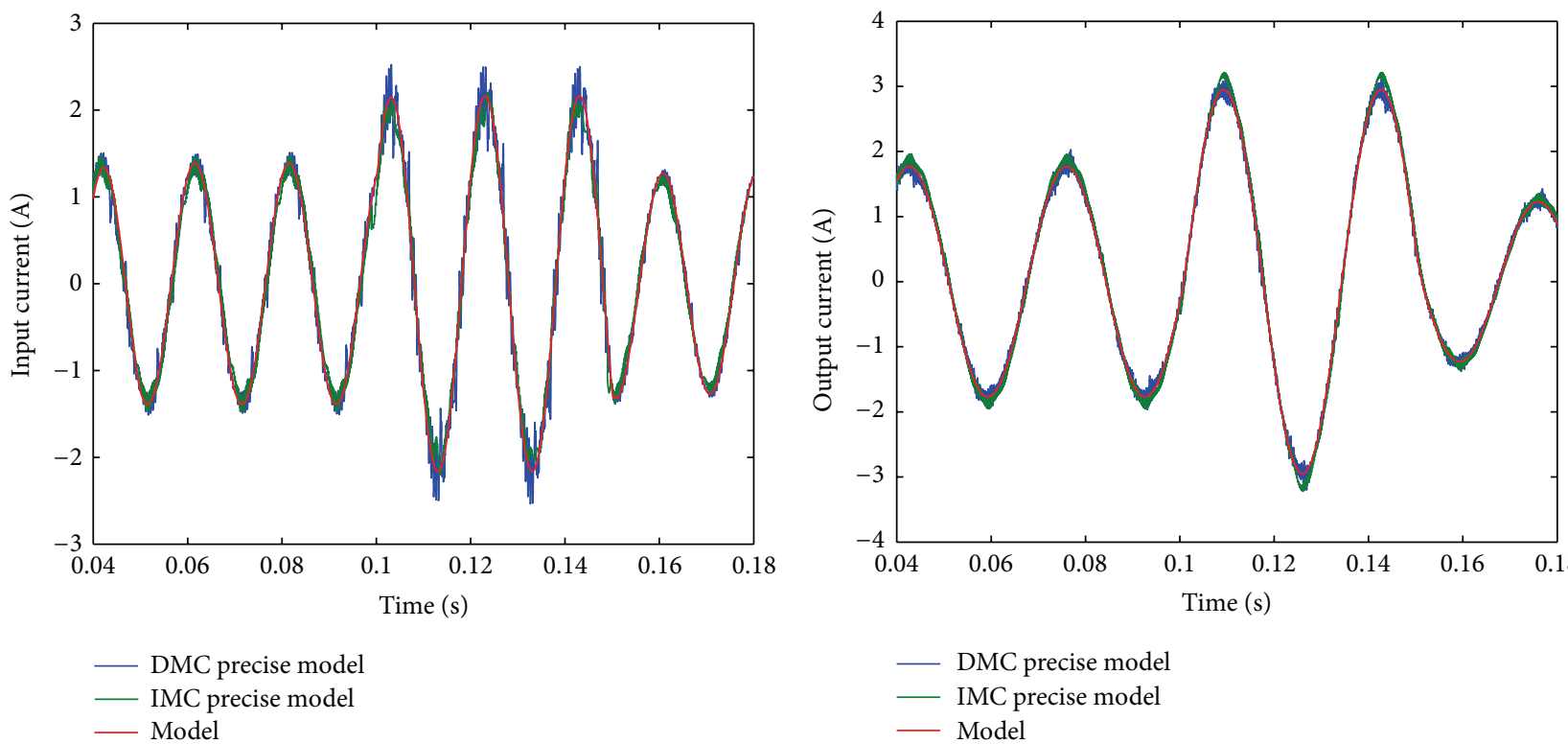

(b)

(c)

Figure 3: (a) Voltage ratio, (b) input current, and (c) output current of the detailed direct and indirect matrix converter and the proposed model.

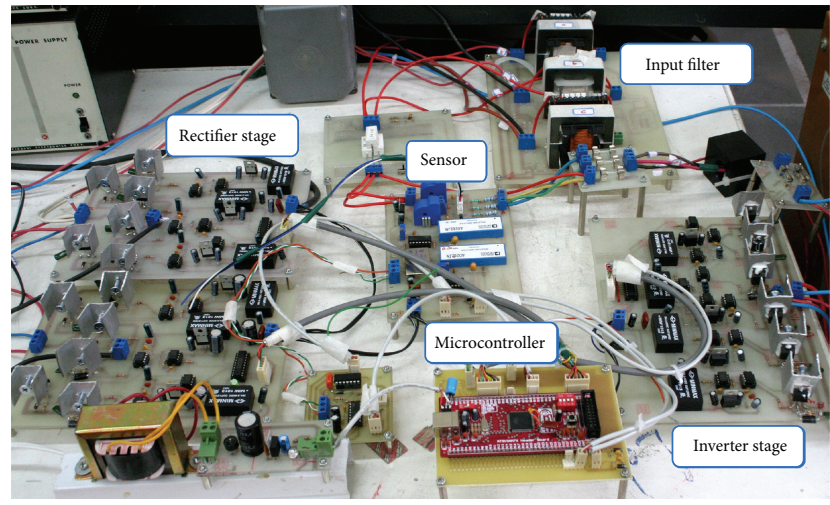

FIGURE 4: Experimental setup.

switching frequency and greater than grid frequency. The filter resistor is chosen to be $12 \Omega$ to increase the damping effect without adding excessive losses to the system. The MC over current protection is performed by fuses at input side of the filter which disconnect MC from grid if the input currents exceed $5 \mathrm{~A}$. Inductor and resistor of load are chosen
TABLE 1: Benchmark system parameters.

\begin{tabular}{lcc}
\hline Parameter & & Value \\
\hline$V_{i}$ & Source & $70 \mathrm{~V}$ (phase) \\
Frequency $\left(f_{s}\right)$ & & $50 \mathrm{~Hz}$ \\
\hline & & \\
$L$ & Input filter & $1.0 \mathrm{mH}$ \\
$R$ & & $12 \Omega$ \\
$C$ & & $40 \mu \mathrm{F}$ \\
\hline & Load & \\
$L$ & & $2.0 \mathrm{mH}$ \\
$R$ & & $10 \Omega$ \\
\hline
\end{tabular}

such that maximum input currents kept below $5 \mathrm{~A}$. Threephase load configuration is star. Figure 3(b) shows the input current of the precise direct and indirect matrix converter models considering the switching behavior of the converter and that of the proposed model. The voltage ratio $(q)$ is varied during simulation as shown in Figure 3(a). Considering $t$ as 


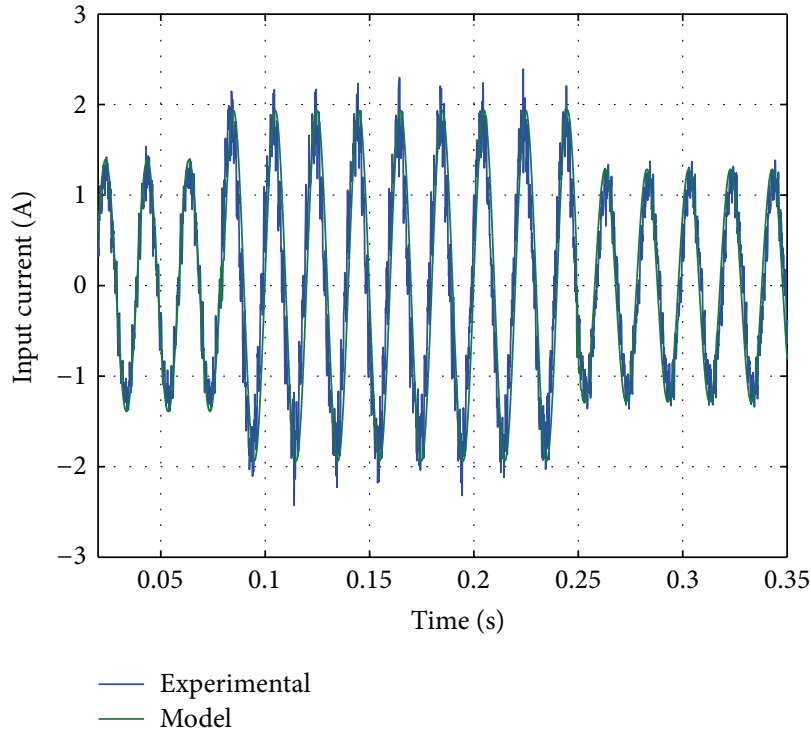

(a)

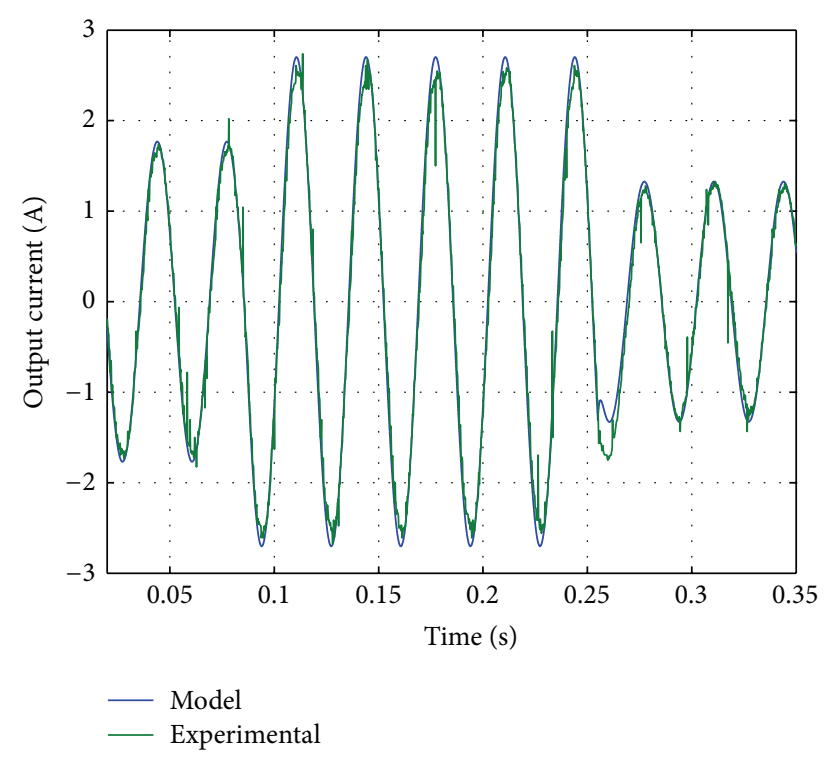

(b)

FIGURE 5: (a) Input, and (b) output current of the proposed model and the experimental setup.

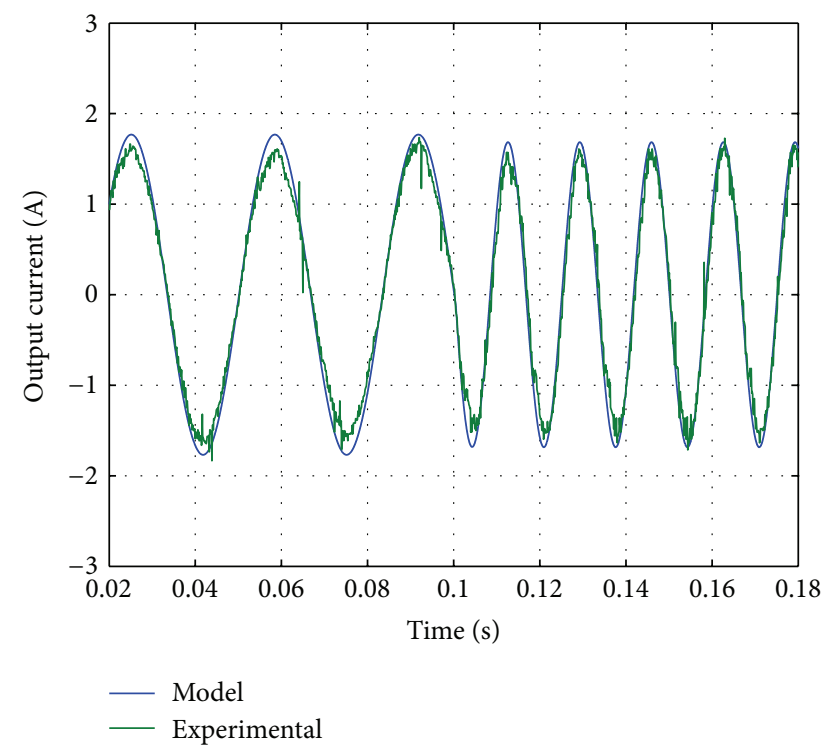

FIGURE 6: MC output current.

the simulation time, the voltage ratios are 0.5 for $t<0.1 \mathrm{sec}$, 0.86 for $0.1<t<0.15 \mathrm{sec}$, and 0.36 for $t>0.15 \mathrm{sec}$. The dynamic model current, as expected, does not contain the switching harmonics. However, the $50 \mathrm{~Hz}$ components of the precise and proposed model are close to each other and the step changes of the voltage ratio have been tracked. The same statement is also true for the output current shown in Figure 3(c). Therefore, the simulations results validate the proposed model.

Moreover, Table 2 shows the simulation time step $\left(T_{\text {sim }}\right)$ for the precise and proposed model. Considering the switching frequency, $T_{\text {sim }}$ should be at least ten times smaller than

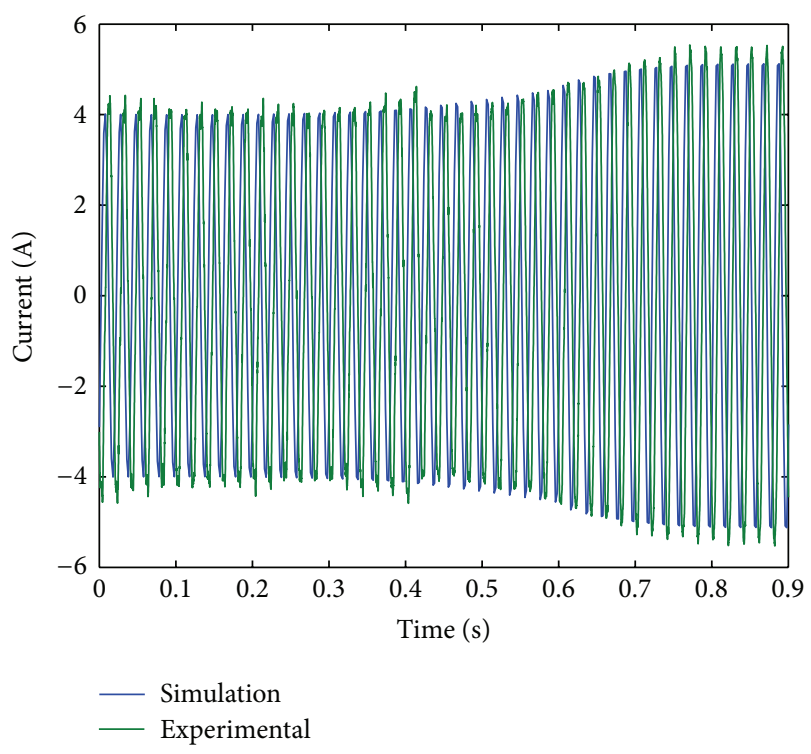

FIGURE 7: SCIM current.

the switching period $(50 \mu \mathrm{s})$. To establish a precise base for comparison, first $T_{\text {sim }}$ is set equal to $2 \mu \mathrm{s}$. Increasing $T_{\text {sim }}$ leads to acceptable results for $T_{\text {sim }} \leq 25 \mu \mathrm{s}$ for the precise model case. On the other hand, using the proposed model, $T_{\text {sim }}$ can be increased up to $500 \mu \mathrm{s}$ without losing the precision. Therefore, the simulation time can be decreased more than ten times.

\section{Experimental Results}

Attempts have been made to provide a prototype laboratory setup to test the accuracy of the proposed model. Figure 4 


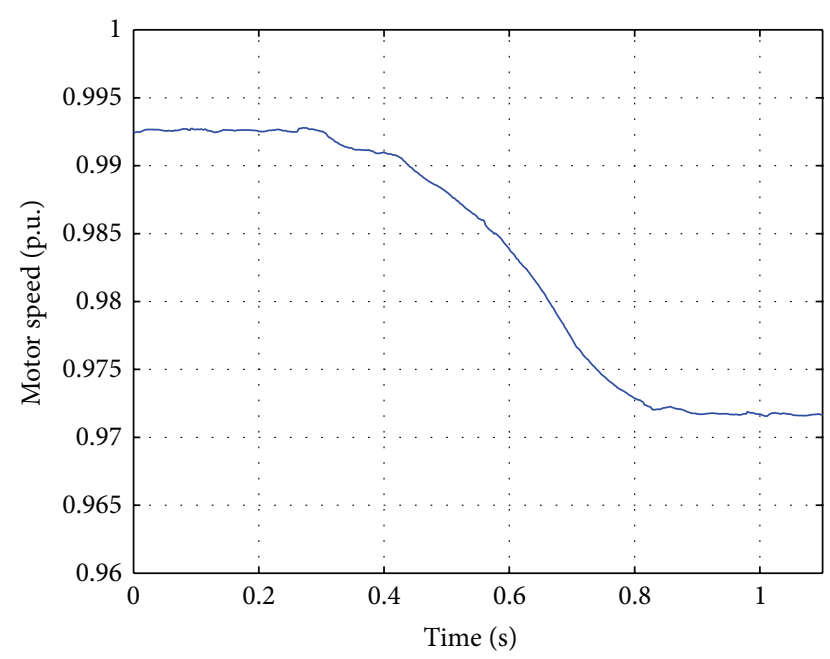

Figure 8: SCIM speed.
TABLE 2: Simulation time step for the precise and proposed model.

\begin{tabular}{lc}
\hline Model & $\begin{array}{c}\text { Simulation time } \\
\text { step }\left(T_{\text {sim }}\right)\end{array}$ \\
\hline Precise model with conservative time step & $2 \mu \mathrm{s}$ \\
Precise model maximum time step & $25 \mu \mathrm{s}$ \\
Proposed model maximum time step & $500 \mu \mathrm{s}$ \\
\hline
\end{tabular}

TABLE 3: SCIM parameters.

\begin{tabular}{lc}
\hline Parameter & Value \\
\hline$X_{m}$ & $73.44 \Omega$ \\
$X_{1}, X_{2}$ & $4.56 \Omega$ \\
$R_{s}, R_{r}$ & $2 \Omega$ \\
$f$ & $50 \mathrm{~Hz}$ \\
$V_{\text {nominal }}$ & $380 \mathrm{~V}$ \\
$P_{\text {nominal }}$ & $1.5 \mathrm{~kW}$ \\
\hline
\end{tabular}

shows that the setup was used to implement the matrix converter. The rectifier and inverter stages, the input filter, and the microcontroller unit are specified in this figure.

The SVM algorithm is implemented using an ARM based microcontroller (SAM7X256 from ATMEL) which has $55 \mathrm{MHz}$ clock frequency. The development tool used for the ARM is Keil $\mu$ Vision version 4.0. The MCU generates 12 gate pulses for the rectifier and inverter stages. Two ADC channels are used to read sensors which measure the matrix converter input voltages. Two line voltages are measured by AD202 isolation amplifier (from Analog Device) and the third line voltage is calculated considering a balanced three-phase source. The MC is implemented using 18 IGBT switches provided by Fuji electric (1MBH30D). The switching frequency $\left(f_{s}\right)$ is $2 \mathrm{kHz}$. A RLC filter $(R=12 \Omega, L=1 \mathrm{mH}$, and $C=20 \mu \mathrm{F}$ ) is connected to the MC input side to reduce the switching harmonics. The load is a three-phase balanced $\mathrm{RL}(R=20 \Omega$ and $L=20 \mathrm{mH})$ with star configuration. The input grid and output voltage frequencies are $f_{i}=50$ and $f_{o}=30 \mathrm{~Hz}$.

Figure 5 shows the proposed matrix converter model and the experimental input and output currents. The voltage ratio is changed from 0.5 to 0.79 at $0.08 \mathrm{sec}$ and from 0.79 to 0.39 at $0.25 \mathrm{sec}$. The input side currents (Figure 5(a)) of the experimental setup and that of the proposed model have a good agreement. The model can predict the MC input current dynamic variations precisely. However, because of the parasitic resistance of the input filter inductor and the switching losses, the actual current is smaller than the dynamic model current.

The output current of the actual MC and the proposed model is shown in Figure 5(b). The model does not generate the switching frequency components. Moreover, the actual output current is smaller than the model current because of the voltage drop over switches, the conduction resistor of the switches, and the voltage drop over the input filter parasitic resistor.
Figure 6 shows how the output current of the model and the actual $\mathrm{MC}$ will vary following a step change in the output frequency. At $0.1 \mathrm{sec}$, the output frequency is increased from 30 to $60 \mathrm{~Hz}$. The model output current tracks the actual MC current precisely.

In another application of the proposed model, a squirrel cage induction motor (SCIM) driven by a MC is tested. The motor parameters are presented in Table 3 . A $2.1 \mathrm{~kW}$ wound rotor induction motor (WRIM) is used as a dynamic load. The motor voltage is decreased from $200 \mathrm{~V}$ to $110 \mathrm{~V}$ during $0.4 \mathrm{sec}$. One phase of the motor current is shown in Figure 7. The proposed model is used in simulations. Comparison of the simulation and experimental results shows that the dynamic model can predict the MC dynamic operation with a good precision. Moreover, motor speed in experimental test is depicted in Figure 8. The speed is decreased because of the voltage drop.

\section{Conclusion}

Owing to the complicated modulation algorithm and the high switching frequency (up to tens of $\mathrm{kHz}$ ), analysis and simulation of the MC based systems become a hard and timeconsuming task. Therefore, based on the dynamic equations of the MC, an equivalent circuit model has been developed to simplify the MC analysis and accelerate the simulations. The model is independent of the MC type (direct or indirect) and the modulation algorithm. Simulation and experimental results have shown the validity and precision of the proposed model to predict the MC fundamental frequency behavior.

\section{Conflict of Interests}

The authors declare that there is no conflict of interests regarding the publication of this paper. 


\section{References}

[1] J. W. Kolar, T. Friedli, F. Krismer, and S. D. Round, "The essence of three-phase AC/AC converter systems," in Proceedings of the 13th International Power Electronics and Motion Control Conference (EPE-PEMC '08), pp. 27-42, Poznan, Poland, September 2008.

[2] E. Ibarra, J. Andreu, I. Kortabarria et al., "New fault tolerant matrix converter," Electric Power Systems Research, vol. 81, no. 2, pp. 538-552, 2011.

[3] P. W. Wheeler, J. Rodríguez, J. C. Clare, L. Empringham, and A. Weinstein, "Matrix converters: a technology review," IEEE Transactions on Industrial Electronics, vol. 49, no. 2, pp. 276288, 2002.

[4] C. Klumpner, P. Nielsen, I. Boldea, and F. Blaabjerg, "A new matrix converter motor (MCM) for industry applications," IEEE Transactions on Industrial Electronics, vol. 49, no. 2, pp. 325-335, 2002.

[5] X. Huang, A. Goodman, C. Gerada, Y. Fang, and Q. Lu, "A single sided matrix converter drive for a brushless DC motor in aerospace applications," IEEE Transactions on Industrial Electronics, vol. 59, no. 9, pp. 3542-3552, 2012.

[6] M. H. Abardeh and R. Ghazi, "A new configuration for dynamic voltage restorer based-on matrix converter," in Proceedings of the 45th International Universities' Power Engineering Conference (UPEC '10), pp. 1-6, Cardiff, UK, September 2010.

[7] B. T. Ooi and M. Kazerani, "Voltage-source matrix converter as a controller in flexible AC transmission systems," IEEE Transactions on Power Delivery, vol. 13, no. 1, pp. 247-253, 1998.

[8] J. Monteiro, J. F. Silva, S. F. Pinto, and J. Palma, "Matrix converter-based unified power-flow controllers: advanced direct power control method," IEEE Transactions on Power Delivery, vol. 26, no. 1, pp. 420-430, 2011.

[9] H. Nikkhajoei and M. R. Iravani, "A matrix converter based micro-turbine distributed generation system," IEEE Transactions on Power Delivery, vol. 20, no. 3, pp. 2182-2192, 2005.

[10] X. Liu, P. C. Loh, P. Wang, F. Blaabjerg, Y. Tang, and E. A. A. Ammar, "Distributed generation using indirect matrix converter in reverse power mode," IEEE Transactions on Power Electronics, vol. 28, no. 3, pp. 1072-1082, 2013.

[11] S. M. Barakati, M. Kazerani, and J. D. Aplevich, "Maximum power tracking control for a wind turbine system including a matrix converter," IEEE Transactions on Energy Conversion, vol. 24, no. 3, pp. 705-713, 2009.

[12] H. Hojabri, H. Mokhtari, and L. Changa, "Reactive power control of permanent-magnet synchronous wind generator with matrix converter," IEEE Transactions on Power Delivery, vol. 28, no. 2, pp. 575-584, 2013.

[13] D. Casadei, G. Serra, A. Tani, and L. Zarri, "Matrix converter modulation strategies: a new general approach based on spacevector representation of the switch state," IEEE Transactions on Industrial Electronics, vol. 49, no. 2, pp. 370-381, 2002.

[14] K. Kobravi, R. Iravani, and H. A. Kojori, “Three-leg/four-leg matrix converter generalized modulation strategy-part I: a new formulation," IEEE Transactions on Industrial Electronics, vol. 60, no. 3, pp. 848-859, 2013.

[15] K. Kobravi, R. Iravani, and H. A. Kojori, “Three-leg/fourleg matrix converter generalized modulation strategy-part II: implementation and verification," IEEE Transactions on Industrial Electronics, vol. 60, no. 3, pp. 860-872, 2013.
[16] L. Helle, K. B. Larsen, A. H. Jorgensen, S. Munk-Nielsen, and F. Blaabjerg, "Evaluation of modulation schemes for threephase to three-phase matrix converters," IEEE Transactions on Industrial Electronics, vol. 51, no. 1, pp. 158-171, 2004.

[17] P. T. Krein, J. Bentsman, R. M. Bass, and B. L. Lesieutre, "On the use of averaging for the analysis of power electronic systems," IEEE Transactions on Power Electronics, vol. 5, no. 2, pp. 182190, 1989.

[18] M. K. Kazimierczuk and D. Czarkowski, "Application of the principle of energy conservation to modeling the PWM converters," in Proceedings of the 2nd IEEE Conference on Control Applications, pp. 291-296, September 1993.

[19] H. Nikkhajoei, A. Tabesh, and R. Iravani, "Dynamic model of a matrix converter for controller design and system studies," IEEE Transactions on Power Delivery, vol. 21, no. 2, pp. 744-754, 2006.

[20] F. Gao and M. R. Iravani, "Dynamic model of a space vector modulated matrix converter," IEEE Transactions on Power Delivery, vol. 22, no. 3, pp. 1696-1705, 2007.

[21] S. M. Barakati, Modeling and controller design of a wind energy conversion system including a matrix converter [Ph.D. thesis], University of Waterloo, 2008.

[22] H. Hojabri, H. Mokhtari, and L. Chang, "A generalized technique of modeling, analysis, and control of a matrix converter using SVD," IEEE Transactions on Industrial Electronics, vol. 58, no. 3, pp. 949-959, 2011.

[23] E. Ibarra, I. Kortabarria, J. Andreu, E. Planas, and I. M. de Alegría, "A fast and accurate simulation method for matrix converters," in Proceedings of the 5th IET International Conference on Power Electronics, Machines and Drives (PEMD '10), pp. 1-6, Brighton, UK, April 2010.

[24] L. Wei and T. A. Lipo, "A novel matrix converter topology with simple commutation," in Proceedings of the 36th IAS Annual Meeting on Industry Applications, vol. 3, pp. 1749-1754, Chicago, Ill, USA, October 2001. 

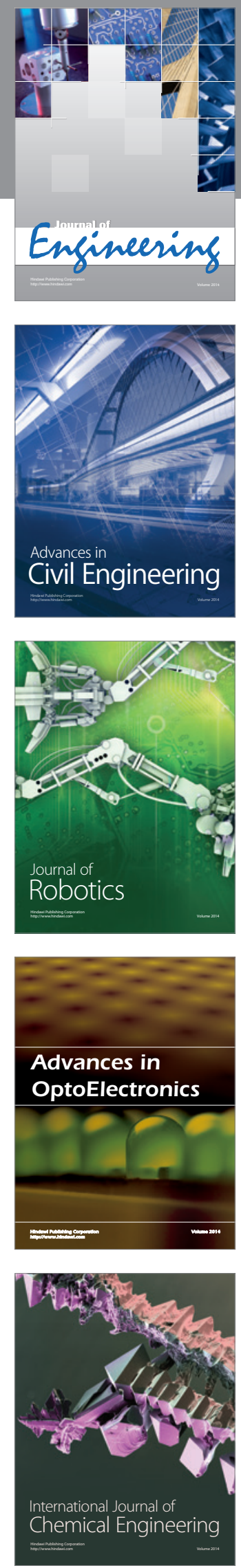

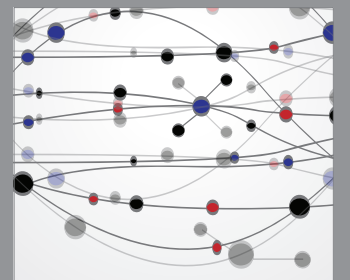

The Scientific World Journal
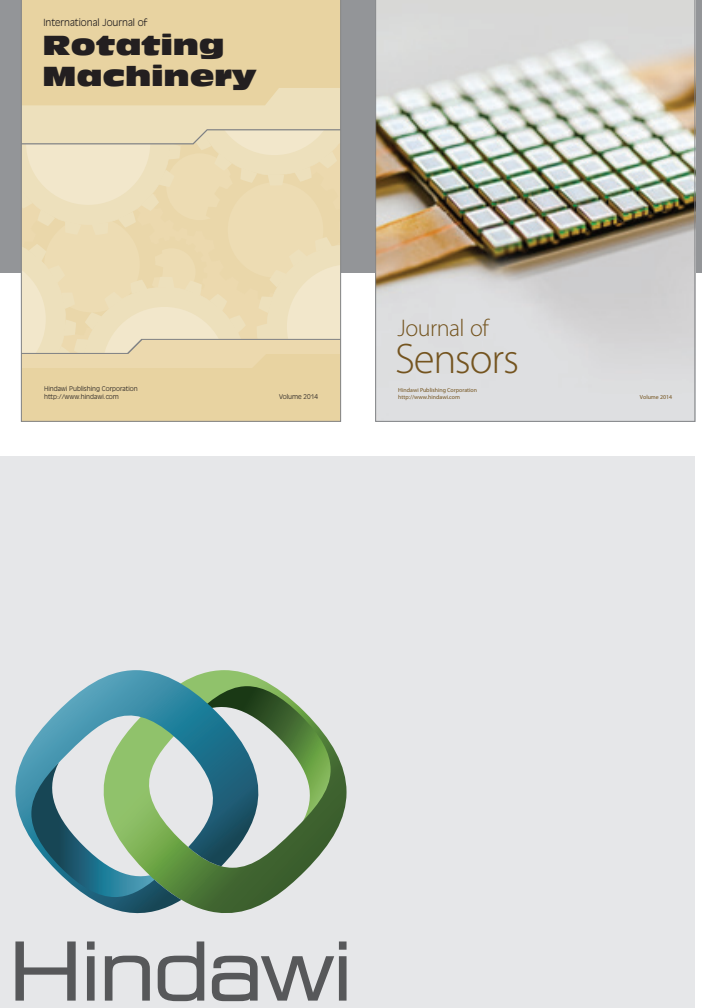

Submit your manuscripts at http://www.hindawi.com
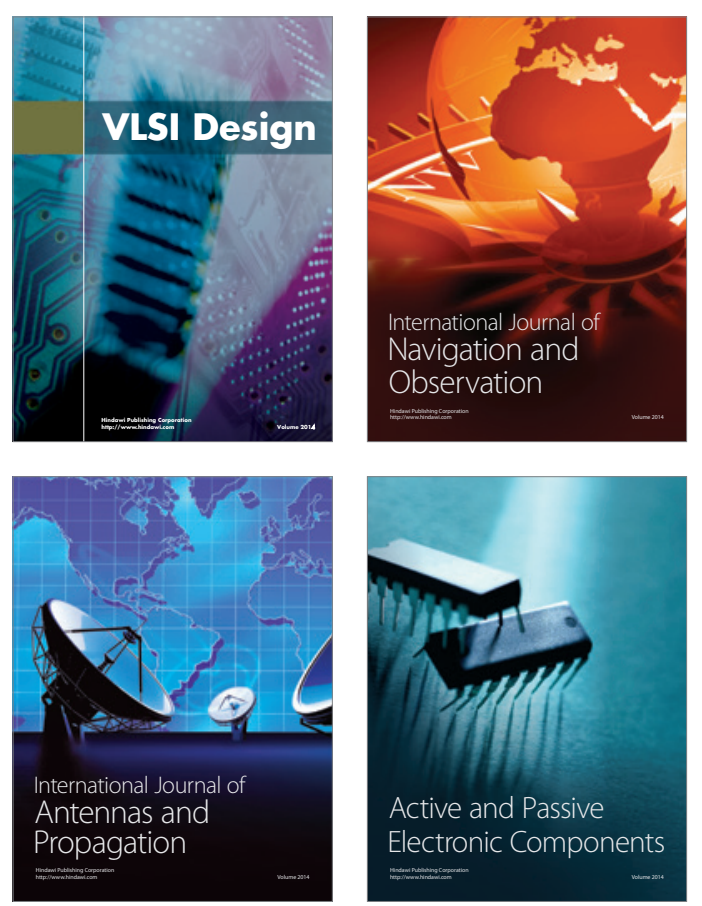
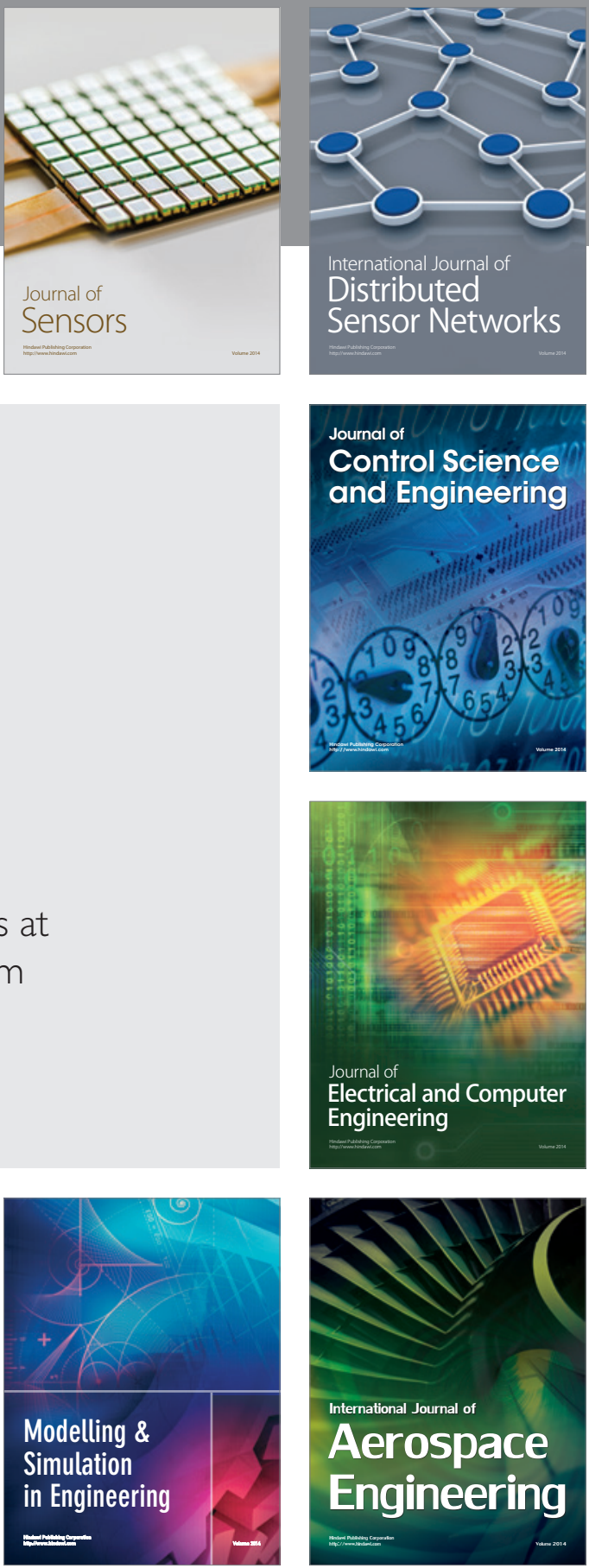

Journal of

Control Science

and Engineering
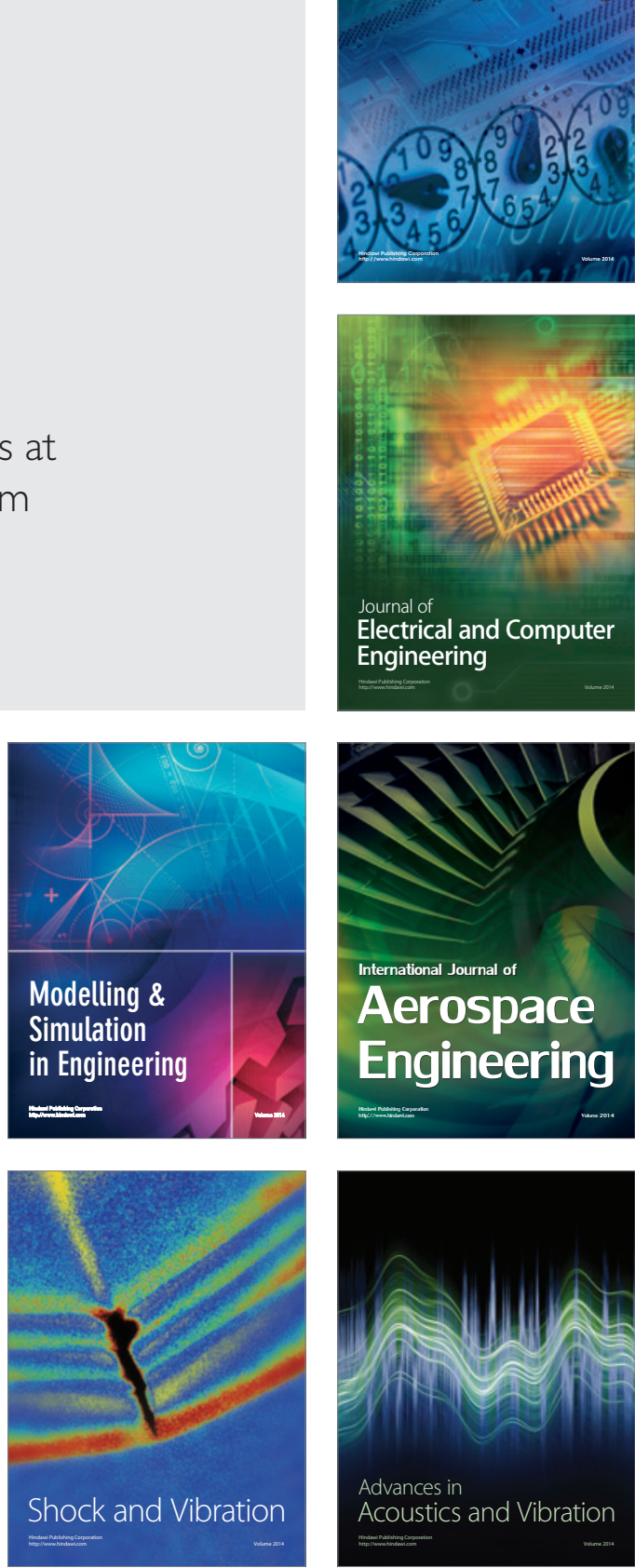